\title{
Hypocalcemia after Total Thyroidectomy - A Prospective Study
}

\author{
N. Saleem Abdul Kuthus ${ }^{1}$, B. Sivakumar ${ }^{2}$ \\ ${ }^{1}$ Assistant Professor, Department of General Surgery, Pudukottai Government Medical College and Hospital, Tamilnadu, \\ ${ }^{2}$ Assistant Professor, Department of General Surgery, Pudukottai Government Medical College and Hospital, Tamilnadu, \\ India
}

Corresponding author: Dr. B. Sivakumar M.S, Assistant Professor, Department of General Surgery, Pudukottai Government Medical College and Hospital, Tamilnadu, India

DOI: http://dx.doi.org/10.21276/ijcmsr.2019.4.3.48

How to cite this article: N. Saleem Abdul Kuthus, B. Sivakumar. Hypocalcemia after total thyroidectomy - a prospective study. International Journal of Contemporary Medicine Surgery and Radiology. 2019;4(3):C220C222.

\section{A B S T R A C T}

Introduction: In order to avoid disease recurrence, total thyroidectomy as a standard procedure for benign thyroid disease has steadily increased over subtotal thyroid resections in the last few decades. However with this more radical approach, an increasing rate of postoperative hypocalcemia is described as well. Current research aimed to study the clinical presentation and incidence of hypocalcaemia following total thyroidectomy

Material and Methods: Patients undergoing total thyroidectomise were included in the study. Patients are undergoing hemithyroidectomy/lobectomy, Primary parathyroid pathologies, Age $<12$ years, previous irradiation to the neck, patient already on calcium supplementation were excluded from the study.

Results: In 30 patients, 11 patients were had postoperative hypocalcemia. 3 in 5 patients with malignancy had hypocalcemia, followed by 2 cases with Hashimoto thyroiditis, 2 cases with Nodular/colloid goiter had hypocalcemia after thyroidectomy. Conclusion To conclude, hypocalcemia occurs relatively commonly following total thyroidectomy and usually results from the inadvertent removal of parathyroid glands or injury or spasm of the blood vessels supplying them.

Keywords Hypocalcemia, Complication, Thyroidectomy

\section{INTRODUCTION}

Hypocalcemia is a common biochemical abnormality that can range in severity from being asymptomatic in mild cases to presenting as an acute life-threatening crisis. ${ }^{1}$ Hypocalcaemia may be an asymptomatic laboratory finding or a life-threatening metabolic disturbance. ${ }^{2}$ Hypocalcemia caused by transient or definitive hypoparathyroidism was the most frequent complication after thyroidectomy, occurring in $63 \%$ of the cases. ${ }^{3}$ After thyroid surgery, it is a common practice to monitor patients for clinical signs or symptoms of hypocalcemia and to assess both serum calcium and phosphorus levels. The incidence of definitive hypoparathyroidism was relevant after total thyroidectomy. It was less relevant after subtotal resections, and its incidence slightly increased after operations for tumor pathology (3.3\%). The problem of how many parathyroids must be preserved to maintain a normal serum calcium level remains unresolved. ${ }^{5}$

It was known that a single functioning gland is enough to restore normal parathyroid activity, whereas others believe that the integrity of at least three glands is necessary. ${ }^{6}$ Transient hypocalcemia is one of the most common postoperative complications following thyroid surgery in clinical practice. It has been reported that the rate of postoperative transient hypocalcemia ranges from $6 \%$ to $30 \%$, although there is $\leq 2 \%$ incidence of persistent dysfunction. $^{7}$ The nadir of hypocalcemia often appears within 48 hours after thyroidectomy. ${ }^{8}$ Symptoms are severe and, requiring calcium replacement therapy. Serum calcium levels recover spontaneously within a few months. However, in a few patients, hypoparathyroidism persists after 1 year and may be considered permanent. ${ }^{9}$ The occurrence of permanent hypocalcemia is mainly attributed to postoperative hypoparathyroidism when parathyroid glands are devascularized, injured, or dissected during the surgery. ${ }^{10}$ The hypocalcemia after surgery is related to multiple factors, including surgical technique, the definition of hypocalcemia, criteria of report series, and use of prophylactic calcium supplementation in the perioperative period.

Current research aimed to study the clinical presentation and incidence of hypocalcaemia following total thyroidectomy

\section{MATERIAL AND METHODS}

This prospective study was conducted in the Department of General Surgery at a tertiary care hospital. Informed consent and Institutional Ethics committee approval was obtained. All patients undergoing thyroidectomy surgeries were included in the study. Data will be collected from the patients undergoing total thyroidectomise by meticulous history taking, careful clinical examination, appropriate radiological, haematological investigations including serum calcium and serum albumin, operative findings and follow- 
up of the cases will be done after surgery for postoperative hypocalcemia. Patients are undergoing hemithyroidectomy/ lobectomy, Primary parathyroid pathologies, Age < 12 years, previous irradiation to the neck, patient already on calcium

\begin{tabular}{|l|c|}
\hline Sex of study population & Number of patients \\
\hline Male & 3 \\
\hline Female & 27 \\
\hline Total & 30 \\
\hline \multicolumn{2}{|c|}{ Table-1: Description of study patients } \\
\hline
\end{tabular}

\begin{tabular}{|l|c|}
\hline Age distribution of study population & Number of patients \\
\hline 12 to 30 years & 9 \\
\hline 31 to 40 years & 9 \\
\hline 41 to 50 years & 7 \\
\hline More than 50 years & 4 \\
\hline Total & 30 \\
\hline \multicolumn{2}{|c|}{ Table-2: Age distribution of study patients } \\
\hline
\end{tabular}

\begin{tabular}{|l|c|}
\hline Indications & Number of patients \\
\hline Malignancy & 5 \\
\hline Toxic features & 8 \\
\hline Swelling/Goitre & 18 \\
\hline Total & 30 \\
\hline \multicolumn{2}{|c|}{ Table-3: Preoperative indications of total thyroidectomy } \\
\hline
\end{tabular}

\begin{tabular}{|l|c|}
\hline $\begin{array}{l}\text { Postoperative final diagnosis based on HPE } \\
\text { report }\end{array}$ & $\begin{array}{c}\text { Number of } \\
\text { Cases studied }\end{array}$ \\
\hline Thyroid malignancy & 3 \\
\hline Thyroid adenomas & 6 \\
\hline Toxic MNG & 2 \\
\hline Graves disease & 2 \\
\hline Hashimoto thyroiditis & 11 \\
\hline Lymphocytic thyroiditis & 1 \\
\hline Nodular/colloid goiter & 5 \\
\hline Total no of cases & 30 \\
\hline \multicolumn{2}{|c|}{ Table-4 Postoperative final diagnosis based on HPE report } \\
\hline
\end{tabular}

\begin{tabular}{|l|c|}
\hline Postoperative hypocalcemia in the study & No of patients \\
\hline No & 19 \\
\hline Yes & 11 \\
\hline
\end{tabular}

Table-5: Post-thyroidectomy Hypocalcemia in the study population

\begin{tabular}{|l|c|}
\hline $\begin{array}{l}\text { Postoperative final diagnosis based on HPE } \\
\text { report }\end{array}$ & Hypocalcemia \\
\hline Thyroid malignancy & 3 \\
\hline Thyroid adenomas & 1 \\
\hline Toxic MNG & 1 \\
\hline Graves disease & 1 \\
\hline Hashimoto thyroiditis & 2 \\
\hline Nodular/colloid goiter & 2 \\
\hline Total no of cases & 11 \\
\hline $\begin{array}{l}\text { Table-6: Distribution of diagnosis in post operative hypocalce- } \\
\text { mia }\end{array}$ \\
\hline
\end{tabular}

supplementation were excluded from the study.

\section{RESULTS}

In this study 30 patients underwent for thyroidectomy were studied. Patients with altered calcium before surgery were excluded. 27 female patients and 3 males patients were included (table-1). 18 patients between 12 to 40 years age patients were underwent thyroidectomy (table-2). 18 patients with swelling/goiter, 8 patients with toxic features and 5 patients with malignancy were underwent thyroidectomy (table-3). Bases on histopathological report Hashimoto thyroiditis were higher in our study. 11 patients $(36.6 \%)$ had hypocalcemia after thyroidectomy (table-4). 3 in 5 patients with malignancy had hypocalcemia, followed by 2 cases with Hashimoto thyroiditis, 2 cases with Nodular/colloid goiter had hypocalcemia after thyroidectomy. According to age distribution higher incidence of hypocalcemia occurred in patients between 12 to 35 years (table-5,6).

\section{DISCUSSION}

All forms of thyroid diseases are much more frequently observed in women than men, although the reasons are still not completely elucidated. ${ }^{11}$ It is greatest during reproductive age and drops from five and more in patients aged 20-24, to 3.4 in patients aged $35-44$ to one in patients over $80 . .^{12}$ The effects of female gonadal hormones and $\mathrm{X}$ chromosome inactivation on the thyroid gland and immune system greatly contribute to the female predilection of autoimmune thyroid diseases. The former mainly include prolactin and estrogen. The direct actions of estrogen on the thyroid tissue contribute to the development of thyroid goiter, nodule and cancer in women. ${ }^{13}$ In this present study it is seen that females contribute more to this disorder. It is also noticed that in women below 40 years of age group, the disease is more prevalent which is evident from our results. Reports indicate that the incidence of benign and malignant lesions in surgically treated thyroid swellings depends on the person's lifestyle and varies widely from one geographical area to another. The prevalence of postoperative hypocalcemia following thyroidectomy which may be temporary or permanent ranges from $0 \%$ to $83 \%$, with the highest incidence seen in patients undergoing total thyroidectomy for cancer (28\%) and in those who underwent subtotal thyroidectomy for thyrotoxicosis (23\%). ${ }^{14}$ On the contrary, the incidence of hypocalcemia is found to be lowest in patients undergoing subtotal thyroidectomy for other diseases (1.5\%) and lobectomy (0\%). ${ }^{15}$ In this current study the postoperative hypocalcemia is also found in less in number compared to various literature reported till date. The percentage of total thyroidectomies being performed for various thyroid diseases has increased significantly in recent years. Initially, the risks which were associated with major surgeries to treat thyroid disease prevented the surgeons from performing total thyroidectomies. Although the use or risks associated with total thyroidectomy remain controversial it is being performed increasingly. It was well explained how iodine treatment in multinodular goiter might be a good alternative to surgery. ${ }^{16}$ In older patients, subtotal thyroidectomy may be the best optional procedure so as to avoid their total and permanent dependence on 
drugs. This study focused on investigating the postoperative hypocalcemia but it was not analyzed due to the compliance of permanent hypocalcemia. The incidence of postoperative hypocalcemia was nearly $27 \%$. In the available literature the incidence of postoperative hypocalcemia was ranging from $30-80 \% .^{17}$

\section{CONCLUSION}

Post-thyroidectomy transient hypocalcaemia is a frequent complication which can be prevented with preoperative preparation of patients with extreme caution and preoperative meticulous dissection, prompt identification of parathyroids and postoperative frequent monitoring of serum calcium and early treatment can prevent significant morbidity.

\section{REFERENCES}

1. Fong J, Khan A. Hypocalcemia: updates in diagnosis and management for primary care. Can Fam Physician. 2012; 58(2):158-162.

2. Cooper, M. S., \& Gittoes, N. J. Diagnosis and management of hypocalcaemia. BMJ (Clinical research ed.), 2008; 336(7656), 1298-1302.

3. Tredici P, Grosso E, Gibelli B, Massaro MA, Arrigoni C, Tradati N. Identification of patients at high risk for hypocalcemia after total thyroidectomy. Acta Otorhinolaryngol Ital. 2011; 31(3):144-148.

4. Sturniolo G, Lo Schiavo MG, Tonante A, D'Alia C, Bonanno L. Hypocalcemia and hypoparathyroidism after total thyroidectomy: a clinical biological study and surgical considerations. Int J Surg Investig. 2000; 2(2):99-105.

5. Yano Y, Masaki C, Sugino K, et al. Serum intact parathyroid hormone level after total thyroidectomy or total thyroidectomy plus lymph node dissection for thyroid nodules: report from 296 surgical cases. Int J Endocrinol Metab. 2012;10(4):594-598.

6. Erbil, Y, Barbaros, U, Ozbey, N, Aral, F, Özarmağan S. Risk factors of incidental parathyroidectomy after thyroidectomy for benign thyroid disorders. International Journal of Surgery 2009; 7(1), 58-61.

7. Chang YK, Lang BHH. To identify or not to identify parathyroid glands during total thyroidectomy. Gland Surg. 2017;6(Suppl 1):S20-S29.

8. Noureldine SI, Genther DJ, Lopez M, Agrawal N, Tufano RP. Early predictors of hypocalcemia after total thyroidectomy: an analysis of 304 patients using a short-stay monitoring protocol. JAMA Otolaryngol Head Neck Surg. 2014;140(11):1006-1013.

9. Wang YH, Bhandari A, Yang F, et al. Risk factors for hypocalcemia and hypoparathyroidism following thyroidectomy: a retrospective Chinese population study. Cancer Manag Res. 2017;9(3):627-635.

10. Lorente-Poch L, Sancho JJ, Muñoz-Nova JL, SánchezVelázquez P, Sitges-Serra A. Defining the syndromes of parathyroid failure after total thyroidectomy. Gland Surg. 2015;4(1):82-90.

11. Abalovich M, Amino N, Barbour LA, Cobin RH, De Groot LJ, Glinoer D, Mandel SJ, Stagnaro-Green A. Management of thyroid dysfunction during pregnancy and postpartum: an Endocrine Society Clinical Practice Guideline. 2007 J Clin Endocrinol Metab 92:S1-S47.
12. Lu Y,Li J,Li J. Estrogen and thyroid diseases: an update. Minerva Med 2016;107(4):239-44.

13. Zheng L, Yan W, Kong Y, Liang P, Mu Y. An Epidemiological Study of Risk Factors of Thyroid Nodule and Goiter in Chinese Women. International Journal of Environmental Research and Public Health 2015: 12(9), 11608-11620.

14. Padur AA, Kumar N, Guru A, et al. Safety and Effectiveness of Total Thyroidectomy and Its Comparison with Subtotal Thyroidectomy and Other Thyroid Surgeries: A Systematic Review. J Thyroid Res. 2016; 2016:7594615.

15. Shiryazdi SM, Kargar S, Afkhami-Ardekani M, Neamatzadeh H. Risk of postoperative hypocalcemia in patients underwent total thyroidectomy, subtotal thyroidectomy and lobectomy surgeries. Acta Med Iran. 52(3):206-209.

16. Kaniuka, Sonia, Lass, Piotr, Sworczak, Krzysztof. Radioiodine - An attractive alternative to surgery in large non-toxic multinodular goitres. Nuclear medicine review. Central \& Eastern Europe 2009:12(2);23-9.

\section{Source of Support: Nil; Conflict of Interest: None}

Submitted: 09-07-2019; Accepted: 01-09-2019; Published online: 21-09-2019 